\title{
Experimental and Theoretical Evidence for Aromatic Stabilization Energy in Large Macrocycles
}

\author{
Michael Jirásek, Michel Rickhaus, Lara Tejerina, and Harry L. Anderson* \\ Department of Chemistry, University of Oxford, Chemistry Research Laboratory, Oxford, OX1 3TA, UK \\ KEYWORDS. global aromaticity, porphyrin nanorings, annulenes, macrocycles
}

\begin{abstract}
Enhanced thermodynamic stability is a fundamental characteristic of aromatic molecules, yet most previous studies of aromatic stabilization energy (ASE) have been limited to small rings with up to $18 \pi$-electrons. Here we demonstrate that ASE can be detected experimentally in $\pi$-conjugated porphyrin nanorings with Hückel circuits of 76-108 $\pi$-electrons. This conclusion is supported by analyzing redox potentials to calculate the energy change for isodesmic reactions that convert an aromatic ring to an antiaromatic ring, or vice versa. It is also supported by analyzing the energy barriers to conformational equilibria that disrupt aromaticity in the transition state. Both types of experiment indicate that cationic porphyrin nanorings display ASEs of $1-5 \mathrm{~kJ} \mathrm{~mol}^{-1}$. Density functional theory (DFT) calculations reproduce the results for both types of experiment, and predict ASEs in the range 1$16 \mathrm{~kJ} \mathrm{~mol}^{-1}$. The experimental ASE in porphyrin nanorings are compared with an experimental ASE of [18]annulene of approximately $11 \mathrm{~kJ} \mathrm{~mol}^{-1}$, deduced from analysis of the energy barriers to conformational equilibria in [16], [18] and [20]annulene. Calculated energies of isodesmic reactions give an ASE of around $37 \mathrm{~kJ} \mathrm{~mol}^{-1}$ in [18]annulene. This work contributes towards fundamental understanding of aromaticity in large macrocycles.
\end{abstract}

\section{Introduction}

The aromaticity of a molecule can be assessed by at least four criteria: (i) thermodynamic stability, (ii) chemical reactivity, (iii) molecular geometry, and (iv) magnetic characteristics. ${ }^{1}$ One problem with these criteria is that they generally require the properties of the molecule to be compared with those of a hypothetical non-aromatic version of itself, and often there is no clear choice of reference system. Another problem is that different criteria can give contradictory indications.

When textbooks introduce the concept of aromaticity, they invariably start by discussing thermodynamic stability. Conjugated cyclic molecules possessing [4n+2] delocalized $\pi$ electrons (where $n$ is an integer) are expected to be aromatic, and to have increased stability. ${ }^{2}$ Conversely, rings with [4n] $\pi$ electrons are expected to be antiaromatic, and to be destabilized. The 'aromatic stabilization energy' (ASE) is positive for aromatic molecules and negative for antiaromatic ones.

In practice, the magnetic criterion has become the primary test for aromaticity in new molecular structures. ${ }^{3}$ Aromatic molecules manifest a diatropic ring current when placed in an external magnetic field. This diatropic current induces a magnetic field that opposes the external field inside the ring, which can be observed by NMR spectroscopy as a magnetic shielding. Conversely, antiaromatic molecules sustain a paratropic ring current, which has the opposite shielding effects. The main advantages of the magnetic criterion are that the shielding/deshielding effects of diatropic/paratropic ring currents are easy to measure, and they tend to be much greater than other shielding effects, particularly if the probe nucleus is far from the $\pi$-system, so that the choice of non-aromatic reference system is often straightforward.

The principle of aromatic stabilization is widely used to rationalize the reactivity of organic molecules, yet surprisingly few experimental studies have been conducted to quantify ASEs. ${ }^{4}$ Many new large globally aromatic molecules have been reported during the last few years. ${ }^{5-11}$ In a few cases, it has been concluded that the ASEs of $[4 n+2]$ Hückel or [4n] Möbius topologies dictates the conformation, ${ }^{12}$ but no attempts have been made to measure the magnitude of the ASE in any of these systems. We have shown that NMR spectroscopy can be used to detect aromatic and antiaromatic ring currents in porphyrin nanorings, with Hückel electron counts of up to 162 $\pi$-electrons $(4 n+2$ with $n=40){ }^{11 \mathrm{c}}$ Here, we explore the experimental and theoretical evidence for ASE in these large macrocycles, in an attempt to answer the question: Does aromaticity confer measurable thermodynamic stability in large rings with $4 n+2>18$ ? We show that redox potentials provide evidence for ASEs, because the difference in stability between oxidation states $Q+$ and $(Q+2)+$ or $(Q-2)+$ is related to the (anti)aromaticity of these states. We also estimate the magnitudes of the ASEs from the energy barriers for conformational exchange processes that break the aromatic $\pi$-conjugation circuit, particularly by comparing barriers for aromatic and antiaromatic oxidation states, i.e. $Q+v s$. $(Q+2)+$ or $(Q-2)+$. By comparing the ASE of closely related aromatic and antiaromatic systems, we avoid the need for a hypothetical nonaromatic reference system. Density functional theory (DFT) calculations support both these methods of estimating the ASE, although the predicted magnitude of the ASEs (1-16 kJ $\left.\mathrm{mol}^{-1}\right)$ is greater than found experimentally $\left(1-5 \mathrm{~kJ} \mathrm{~mol}^{-1}\right)$. Before analyzing the ASEs of porphyrin nanorings, we briefly consider the concept of ASE in $[N]$ annulenes. 


\section{Aromatic Stabilization Energies of [N]Annulenes}

One of the most interesting differences between the magnetic and energetic criteria for aromaticity is that the ASEs of $[N]$ annulenes decline more steeply than magnetic manifestations of aromaticity with increasing $N$. Simple Hückel molecular orbital (HMO) and perturbation theory predicts that the ring current scales with the area of the ring, ${ }^{13}$ i.e. with $N^{2}$, so it is not surprising that large aromatic rings have substantial ring currents, even when their ASEs are very small. There are many theoretical approaches to calculating the ASE of $[N]$ annulenes as a function of $N$ and they all predict that the ASE decays rapidly, becoming negligible (or constant) by about $N=30 .^{2,14-16}$ This effect is obvious from a FrostMusulin diagram, the simplest HMO model for the $\pi$-orbitals of a conjugated ring: as $N$ increases, the energy levels get closer together and the energy difference between aromatic and antiaromatic species becomes smaller. If we make the approximation that, for large [N]annulenes, the ASE in aromatic $(N=4 n+2)$ rings is the same in magnitude but opposite in sign to the ASE in antiaromatic $(N=4 n)$ rings, then the ASE is predicted by HMO theory to be approximately inversely proportional to $N$, as expressed by equation (1),

$$
\operatorname{ASE}(N) \approx \frac{\beta \pi}{N}
$$

where $\beta$ is the Hückel resonance integral (see SI Section 6.8 for derivation of this equation). This model is extremely crude, but it is a useful reminder that we expect ASE to decrease steeply with increasing $N$, even without considering the conformational disorder and bond-length alternation that inevitably disrupt aromaticity in large annulenes.

When the experimental (or theoretical) heat of formation of an (anti)aromatic compound is known, the ASE can be estimated by constructing a thermodynamic cycle for a hypothetical isodesmic (and ideally hyperhomodesmotic) ${ }^{17}$ reaction that involves breaking the $\pi$-conjugation in the ring. However, even when the heat of formation is known accurately (as is the case for benzene, $\left.{ }^{18} \Delta H_{\mathrm{f}}(\mathrm{g})=82.6 \pm 0.7 \mathrm{~kJ} \mathrm{~mol}^{-1}\right)$, there is uncertainty in the ASE because different isodesmic cycles give different values. For example, experimental estimates of the ASE of benzene range from +90 to $+150 \mathrm{~kJ} \mathrm{~mol}^{-1}$ (and theoretical estimates have a similar spread). ${ }^{2,4}$ The problem is not that ASE is difficult to measure or difficult to define, but that it is difficult to choose between many competing definitions, based on different reference systems. The ASE of benzene compared with 'Kekulé benzene', with three isolated (nonconjugated) double bonds, is about $+150 \mathrm{~kJ} \mathrm{~mol}^{-1}$; this is the total resonance energy. In contrast, the Dewar resonance energy compares benzene with a linear $\pi$-conjugated triene to give an ASE of about $90 \mathrm{~kJ} \mathrm{~mol}^{-1}$; this is the extra stabilization from closure of the aromatic ring. ${ }^{2,16}$

To the best of our knowledge, the largest $\pi$-conjugated macrocycle for which experimental thermochemical data have been used to estimate the ASE is [18]annulene $\left(\mathrm{C}_{18} \mathrm{H}_{18}\right)$. In this case, two wildly different determinations of the heat of formation $\left(\Delta H_{\mathrm{f}}(\mathrm{g})=280 \pm 25 \text { and } 516 \pm 16 \mathrm{~kJ} \mathrm{~mol}^{-1}\right)^{4,19-21}$ lead to estimates of the ASE of 162 and $398 \mathrm{~kJ} \mathrm{~mol}^{-1}$, both defined by comparison with a hypothetical 'Kekulé [18]annulene' in which every double bond is isolated. Various theoretical estimates of the ASE of [18] annulene have been reported, ${ }^{15,22,23}$ and the best approach appears to be to calculate the enthalpy for a homodesmotic reaction of the type shown in Figure 1a. ${ }^{24}$ The energy for conversion $\mathbf{A} \rightarrow \mathbf{C}$ provides an estimate for the
ASE, which can be improved by adding the conversion of $\mathbf{B} \rightarrow \mathbf{D} .^{23,24}$ In terms of the hierarchy of homodesmotic reactions, $\mathbf{A} \rightarrow \mathbf{C}$ is homodesmotic (RC4) whereas $(\mathbf{A}+\mathbf{B}) \rightarrow(\mathbf{C}+\mathbf{D})$ is hyperhomodesmotic (RC5). ${ }^{17}$ Schleyer and coworkers applied the reaction $(\mathbf{A}+\mathbf{B}) \rightarrow(\mathbf{C}+\mathbf{D})$ to estimate the ASEs of antiaromatic $[N]$ annulenes $(N=4 n),{ }^{24}$ but it does not previously appear to have been applied to aromatic $[N]$ annulenes. We used Schleyer's method, in which molecules A-D are constrained to $C_{\mathrm{s}}$ symmetry, to calculate the ASE for $[N]$ annulenes for $N=12-66$ (Figure $1 b$ ) by DFT with the 6$31 \mathrm{G}^{*}$ basis set, using two different hybrid functionals, with correction for zero-point energy (ZPE). In this case, the two functionals B3LYP and LC- $\omega \mathrm{hPBE}(\omega=0.1)$ give similar results. The difference between these functionals is discussed below. Using B3LYP, this approach gives ASEs for [16] and [18] annulene of -23.4 and $+36.9 \mathrm{~kJ} \mathrm{~mol}^{-1}$, respectively.
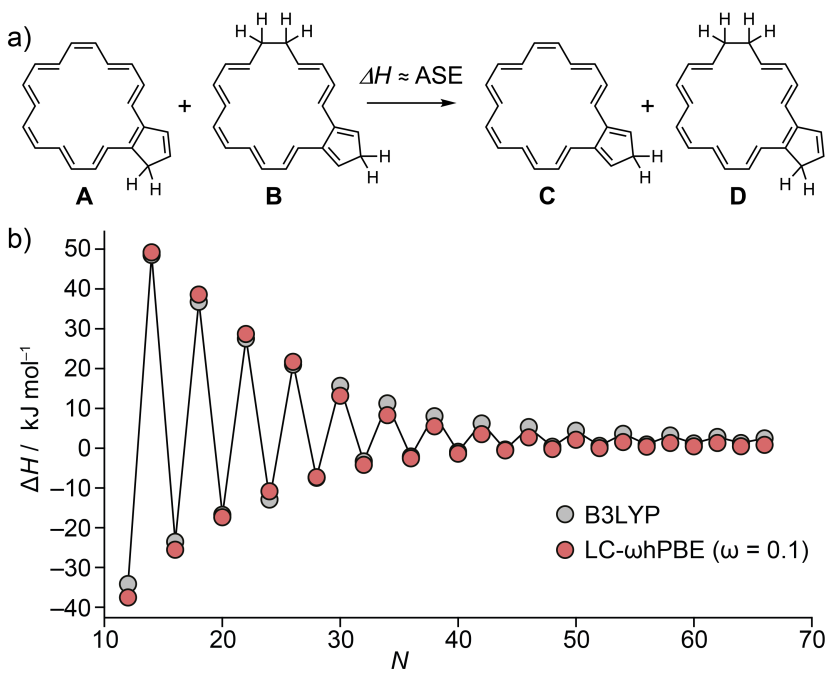

Figure 1. (a) A hyperhomodesmotic reaction for estimating the ASE of $[N]$ annulenes and (b) values of $\Delta H$ calculated for this reaction for with $N=12-66$. The molecular geometries were optimized while constraining $C_{\mathrm{s}}$ symmetry using the $\mathrm{B} 3 \mathrm{LYP} / 6-31 \mathrm{G}^{*}$ and LC- $\omega$ hPBE $(\omega=0.1) / 6-31 \mathrm{G}^{*}$ DFT methods, both with correction for $\mathrm{ZPE}$.

Oth and coworkers estimated the ASE of [18]annulene from the activation energy for conformational exchange of internal and external hydrogen atoms, i.e. exchange of protons $\mathrm{H}_{\mathrm{a}}$ and $\mathrm{H}_{\mathrm{b}}$ in Figure $2 \mathrm{a}$, measured by ${ }^{1} \mathrm{H}$ NMR spectroscopy, giving $\mathrm{ASE} \approx \Delta G^{\ddagger} \approx 67 \mathrm{~kJ} \mathrm{~mol}^{-1} \cdot{ }^{25,26}$ Later, they suggested that this method underestimates the ASE, because the transition state for exchange, in which one alkene unit is twisted out of conjugation, still has the resonance energy of a linear polyene. ${ }^{20,21}$ In other words, the exchange barrier is nearer the Dewar resonance energy ${ }^{2,16}$ than the ASE relative to Kekule [18]annulene. Conversely, other factors may destabilize the transition state, so that $\Delta G^{\ddagger}$ overestimates the ASE, as indicated by the observation that antiaromatic [16] and [20]annulenes also have significant barriers for this type of exchange process, even when the ASE is expected to be negative. Values of $\Delta G^{\ddagger}$ for $[N]$ annulenes $(N=12-24)$ show a clear alternation, with higher barriers for $N=4 n+2$ and lower barriers for $N=4 n$ (Figure 2b) ${ }^{25,27-32}$ If we assume that this alternating pattern reflects the underlying aromatic and antiaromatic ASEs, which make it alternately harder and easier to twist the molecule out of conjugation, then an estimate of the ASE can be made according 
to equation (2), as represented by the lengths of the red arrows in Figure $2 b$.

$$
\operatorname{ASE}(N) \approx \frac{\Delta G^{\ddagger}(N)}{2}-\frac{\left[\Delta G^{\ddagger}(N-2)+\Delta G^{\ddagger}(N+2)\right]}{4}
$$

This approach gives an experimental ASE for [18]annulene of $11 \mathrm{~kJ} \mathrm{~mol}^{-1}$. To the best of our knowledge, the data shown in Figure 2 have not previously been interpreted in this way. There is a high level of uncertainty in this estimate, because many factors may contribute towards the energy barrier, but it is reasonable to assume that the alternating effect seen in Figure $2 \mathrm{~b}$ reflects the alternating sign of the ASE. This estimate of the ASE seems more likely to be correct than the values of 162 and $398 \mathrm{~kJ} \mathrm{~mol}^{-1}$ from thermochemical data, because it is nearer the values from DFT calculations.

a)

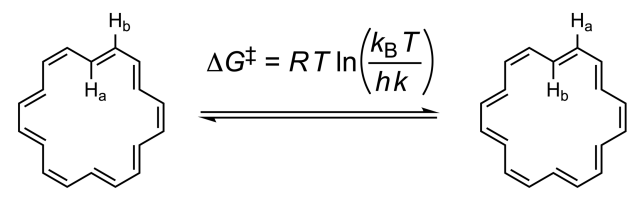

b)

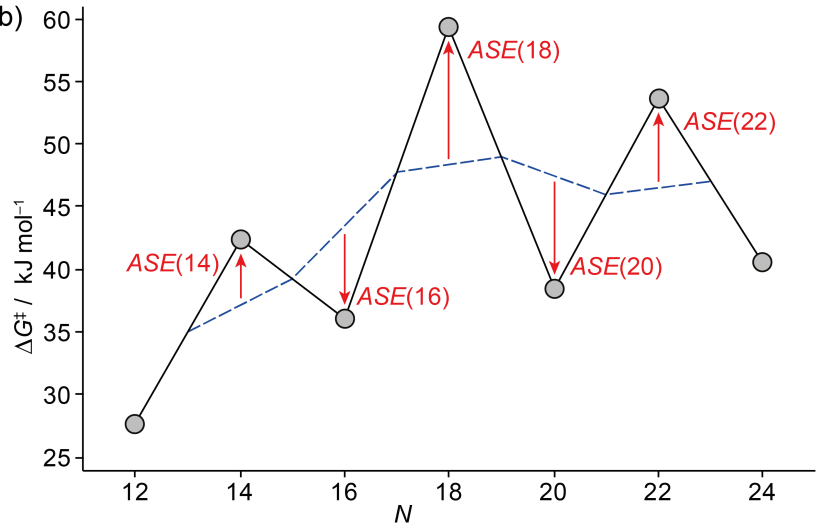

Figure 2. (a) Conformational exchange of inner $\left(\mathrm{H}_{\mathrm{a}}\right)$ and outer $\left(\mathrm{H}_{\mathrm{b}}\right)$ protons in [18] annulene. The Eyring equation gives the energy barrier, $\Delta G^{\ddagger}$, in terms of the gas constant, $R$, the temperature $T$, the Boltzmann constant $k_{\mathrm{B}}$, the Planck constant $h$ and the rate of exchange $k$. (b) Barriers for this type of exchange process for $[N]$ annulenes $(N=12-24)$ from ${ }^{1} \mathrm{H}$ NMR spectroscopy. ${ }^{25,27-32}$ The blue line is drawn between the averages for neighboring points. The lengths of the red arrows is the $A S E(N)$ from equation (2).

\section{Results and Discussion}

\section{Electrochemistry of Nanoring-Template Complexes}

Previously, we used ${ }^{1} \mathrm{H},{ }^{13} \mathrm{C}$ and ${ }^{19} \mathrm{~F}$ NMR spectroscopy and magnetic susceptibility measurements to show that oxidation and reduction can induce global ring currents in porphyrin nanorings. ${ }^{11}$ In every case, the direction of the ring current (aromatic vs. antiaromatic) is correctly predicted by Hückel's rule, which means that the ring current is reversed by changing the oxidation state by $\Delta Q=2$. Here, we investigate whether the ASE associated with global aromaticity is reflected in the redox potentials by studying the electrochemistry of butadiyne-linked nanoring template complexes $\boldsymbol{c}$-P6·T6, $\boldsymbol{c}$ $\mathbf{P 6 ( t )} \cdot \mathbf{T 6}, \boldsymbol{c}$-P7·T7 and $\boldsymbol{c - P 8} \cdot(\mathbf{T 4})_{2}$ (Figure 3). These compounds were synthesized as reported previously. ${ }^{33}$ The truncated six-porphyrin nanoring $\boldsymbol{c}$-P6(t) has one ethyne-link, so that its Hückel electron count is two less that $\boldsymbol{c}$-P6, reversing the direction of the ring current. ${ }^{11 \mathrm{c}}$ The aromatic and antiaromatic oxidation states of these compounds are summarized in Table 1.
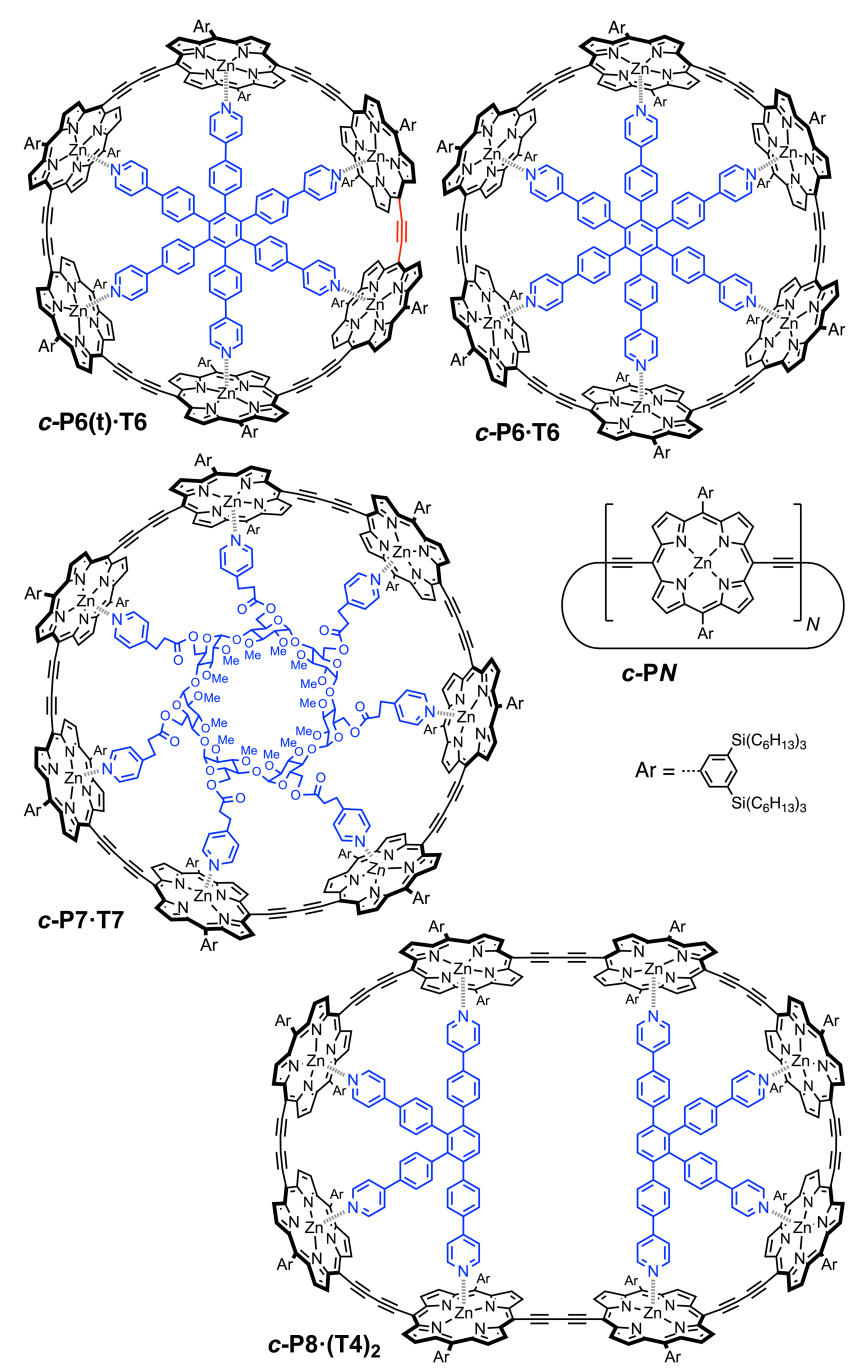

Figure 3. Structures of $c$-P6·T6, $c-\mathbf{P 6}(\mathbf{t}) \cdot \mathbf{T 6}, c-\mathrm{P} 7 \cdot \mathbf{T} 7$ and $c$ P8.(T4) ${ }_{2}$. The template units, T6, T7 and T4, are drawn in blue.

Table 1. Aromatic and antiaromatic forms of selected porphyrin nanoring template complexes deduced from NMR spectroscopy, where $Q$ is the oxidation state.

\begin{tabular}{|c|c|c|c|c|}
\hline$Q$ & $c-\mathrm{P6} \cdot \mathbf{T 6}^{\mathrm{a}, \mathrm{b}}$ & $c-\mathrm{P} 6(\mathrm{t}) \cdot \mathrm{T} 6^{\mathrm{b}}$ & $c-\mathrm{P} 7 \cdot \mathrm{T}^{\mathrm{c}}$ & $c$-P8.(T4) ${ }_{2}{ }^{\mathrm{b}}$ \\
\hline 2 & $\begin{array}{l}82 \pi \\
\text { aromatic }\end{array}$ & $\begin{array}{l}80 \pi \\
\text { antiaromatic }\end{array}$ & - & - \\
\hline 4 & $\begin{array}{l}80 \pi \\
\text { antiaromatic }\end{array}$ & $\begin{array}{l}78 \pi \\
\text { aromatic }\end{array}$ & $\begin{array}{l}94 \pi \\
\text { aromatic }\end{array}$ & $\begin{array}{l}108 \pi \\
\text { antiaromatic }\end{array}$ \\
\hline 6 & $\begin{array}{l}78 \pi \\
\text { aromatic }\end{array}$ & $\begin{array}{l}76 \pi \\
\text { antiaromatic }\end{array}$ & $\begin{array}{l}92 \pi \\
\text { antiaromatic }\end{array}$ & $\begin{array}{l}106 \pi \\
\text { aromatic }\end{array}$ \\
\hline 8 & - & - & - & $\begin{array}{l}104 \pi \\
\text { antiaromatic }\end{array}$ \\
\hline
\end{tabular}

${ }^{a}$ Data from ref 11a. ${ }^{b}$ Data from ref 11c. ${ }^{c}$ This work (see SI for details).

The experimental square-wave voltammogram for oxidation of $\boldsymbol{c - P 6 \cdot T 6}$ to $\boldsymbol{c - P 6} \cdot \mathbf{T 6} \mathbf{6}^{\mathbf{6}}$ was deconvoluted by fitting to the sum of six Gaussian functions (Figure $4 \mathrm{a}$ ). A plot of the peak potential for each redox process $\left(E_{\mathrm{ox}}\right)$ against oxidation state $(Q)$ is almost linear (Figure $4 \mathrm{~b}$ ). The slight deviations from linearity might indicate that the aromatic $2+$ and $6+$ oxidation states are slightly more stable than expected, while the anti- 
aromatic 4+ oxidation state is slightly less stable than expected. However, these deviations from linear behavior are comparable with the experimental uncertainty (ca. $10 \mathrm{mV}$ ) and similar plots for $\boldsymbol{c}-\mathbf{P 6}(\mathbf{t}) \cdot \mathbf{T 6}, \boldsymbol{c}-\mathbf{P 7} \cdot \mathbf{T} 7$ and $\boldsymbol{c}$-P8 $(\mathbf{T} 4)_{2}$ do not show systematic evidence for stabilization of aromatic oxidation states relative to antiaromatic ones (see SI Section 4.5).
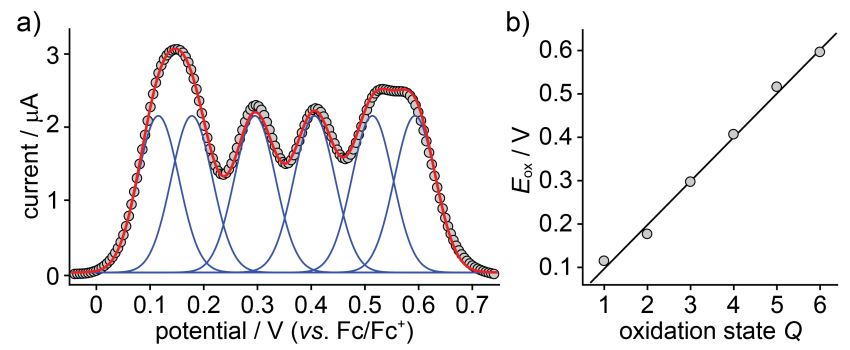

Figure 4. a) Square-wave voltammogram of $\boldsymbol{c}$-P6.T6 (gray circles) measured in $\mathrm{CH}_{2} \mathrm{Cl}_{2}$ at $-45^{\circ} \mathrm{C}$. Sum (red line) of the fit of the individual Gaussian functions (blue lines) allows for an accurate determination the oxidation potential for each state. b) Plot of the oxidation states against the estimated oxidation potentials.

The hypothetical hyperhomodesmotic reaction represented by equation (3) provides a more sensitive test for the electrochemical data:

$$
c-\mathbf{P} N^{Q^{+}}+c-\mathbf{P N}(\mathbf{t}) \rightarrow c-\mathbf{P N}+c-\mathbf{P N}(\mathbf{t})^{Q^{+}}
$$

In this reaction, the charge $Q+$ is switched between two nanorings, $\boldsymbol{c}-\mathbf{P} \boldsymbol{N}$ and $\boldsymbol{c}-\mathbf{P} \boldsymbol{N}(\mathbf{t})$, which differ by two $\pi$-electrons. This process converts an aromatic system to an anti-aromatic one, or vice versa, as the neutral nanorings $(Q=0)$ do not exhibit any global aromaticity.

The oxidation potentials of $\boldsymbol{c}$-P6 and $\boldsymbol{c}$-P6(t) were used to calculate the free-energy change for equation (3) for $N=6$, with $Q=2,4$ and 6, giving the data plotted in Figure 5a. For $Q$ $=2$, the net free energy change is less than the experimental uncertainty, $\left(\Delta G=-1.6 \pm 1.9 \mathrm{~kJ} \mathrm{~mol}^{-1}\right)$. However, the observation that equation (3) is thermodynamically favorable for $Q$ $=4\left(\Delta G=-5.8 \pm 2.7 \mathrm{~kJ} \mathrm{~mol}^{-1}\right)$ and unfavorable for $Q=6(\Delta G$ $\left.=+9.9 \pm 3.3 \mathrm{~kJ} \mathrm{~mol}^{-1}\right)$ suggests that the ASE influences the redox potentials. The magnitude of the ASE can be approximated for half the energy difference, as the effect results from aromaticity in one ring and antiaromaticity in the other, giving $\mathrm{ASE} \approx 2.9 \pm 1.4 \mathrm{~kJ} \mathrm{~mol}^{-1}$ (for $Q=4$ ) and $\mathrm{ASE} \approx 5.0 \pm 1.7 \mathrm{~kJ}$ $\mathrm{mol}^{-1}$ (for $Q=6$ ).

Although $\boldsymbol{c}$-P6(t) is the only truncated nanoring that we have studied experimentally, we have calculated the energy change for equation (3) for $N=5-8$, with $Q=2,4$ and 6, using DFT. We used the $6-31 \mathrm{G}^{*}$ basis set in combination with two different functionals: B3LYP ${ }^{34}$ and long-range corrected LC$\omega$ hPBE $\left(\omega=0.1 \mathrm{a}_{0}{ }^{-1}\right),{ }^{35}$ in both cases with ZPE correction. The qualitative difference between these two hybrid functionals is in the way they introduce Hartree-Fock (HF) exchange to correct for self-interaction error. ${ }^{36}$ In B3LYP, the fraction of HF exchange is set at $20 \%$, whereas in LC- $\omega$ hPBE it is gradually increased up to $100 \%$ as a function of distance according to the range separation parameter $\omega,{ }^{35,37}$ providing a handle to adjust the description of electronic localization. The LC$\omega \mathrm{hPBE}(\omega=0.1)$ functional was chosen as it was benchmarked in a previous study to best reproduce the experimentally observed ring currents in porphyrin nanorings cations. ${ }^{11 \mathrm{c}}$ The B3LYP functional is a popular standard and we have previously used it to qualitatively reproduce observed global ring current effects in nanorings, ${ }^{1 \mathrm{a}, \mathrm{b}}$ however it tends to exaggerate electronic delocalization and global aromaticity. ${ }^{36,38,39}$ The aryl solubilizing groups (Ar in Figure 3) were replaced with hydrogen atoms to reduce the cost of these calculations. The geometries were optimized, and the total energies were corrected for the zero-point energy obtained from the harmonic vibrational frequency calculations (for details see SI Section 6.2). The results (Figure 5b,c) show that both functionals give a clear alternating pattern of energy with $\Delta Q=2$, as expected for the alternating aromaticity of the nanorings, in agreement with the experimental results in Figure 5a. This alternation is superimposed on a positive gradient, indicating that $\boldsymbol{c}-\mathbf{P} \boldsymbol{N}$ is slightly easier to oxidize than $\boldsymbol{c}-\mathbf{P} \boldsymbol{N}(\mathbf{t})$. The magnitude of the ASE estimated from the deviation from a linear rise is $6-10 \mathrm{~kJ}$ $\mathrm{mol}^{-1}$ for B3LYP and $1-5 \mathrm{~kJ} \mathrm{~mol}^{-1}$ for LC- $\omega \mathrm{hPBE}$ (Table S16).
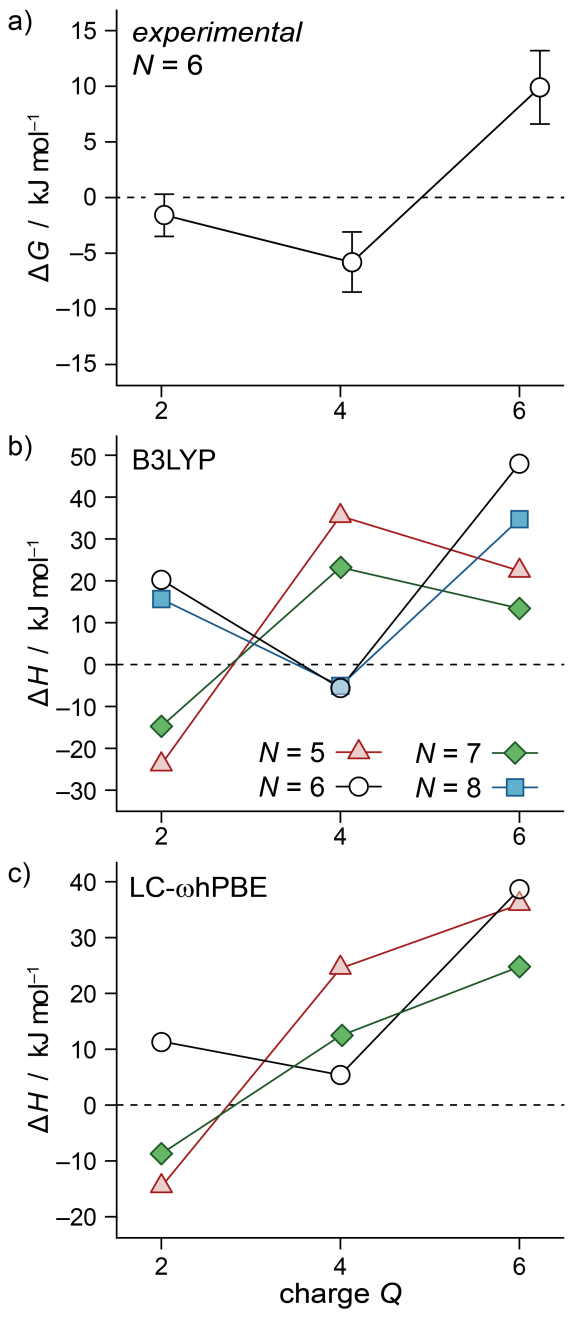

Figure 5. Energy changes for the homodesmotic reaction represented by equation (3). (a) Experimental free energies for $N=6$ from redox potentials; (b) and (c) enthalpies for $N=5-8$, calculated using the $6-31 \mathrm{G}^{*}$ basis set in combination with two different functionals, B3LYP and LC- $\omega$ hPBE $(\omega=0.1)$, both with ZPE correction. (Points are not shown for $N=8$ with LC- $\omega$ hPBE because there was a problem with these calculations; see SI Section 6.2.)

The conclusion from this electrochemical study is that $c$ $\mathbf{P 6}^{\mathbf{4 +}}$ and $\boldsymbol{c}-\mathbf{P 6}^{\mathbf{6}}$ appear to have experimental ASEs of about 3 $\mathrm{kJ} \mathrm{mol}^{-1}$ and $5 \mathrm{~kJ} \mathrm{~mol}^{-1}$, respectively. These values are similar in magnitude to the ASEs predicted by DFT using the LC- 
$\omega \mathrm{hPBE}$ functional, based on gas-phase homodesmotic chargeexchange reactions. Below, we explore the evidence for ASE from the barriers to conformational exchange processes, but first we need to demonstrate that template-free nanorings exhibit global (anti)aromatic ring currents.

\section{Analysis of Aromaticity in Template-Free Nanorings by NMR Spectroscopy}

Bound templates facilitate the investigation of global aromatic ring currents in porphyrin nanoring cations by NMR spectroscopy in three ways: ${ }^{11}$ (a) they hold the macrocycle in a well-defined conformation, (b) they probe magnetic shielding near the center of the nanoring, and (c) they enable resonances from porphyrin sidechains on the inside of the ring to be assigned via the observation of nuclear Overhauser effects (NOEs) to the template. However, the presence of bound templates also brings two disadvantages: (d) they make it more difficult to compare behavior in a homologous series of $\boldsymbol{c}-\mathbf{P} \boldsymbol{N}$ nanorings, because each template has unique features (e.g. T6 vs. T7 in Figure 3; the templates are non-homologous), and (e) they prevent investigation of the effects of aromaticity on conformational flexibility. Here we investigate aromatic ring currents in oxidized nanorings, $\boldsymbol{c}-\mathbf{P} \boldsymbol{N}^{\boldsymbol{Q}^{+}}$with $N=5-8$ and $Q=4$ or 6 (structure in Figure 3), with no bound template. These compounds were synthesized as reported previously. ${ }^{33,40}$ The nanorings are decorated with meso-3,5-bis(trihexylsilyl)phenyl (THS) groups, which increases the solubility and provides two unique NMR probes. One THS group points towards the inside $\left(\mathrm{THS}_{\mathrm{in}}\right)$ and the other towards the outside $\left(\mathrm{THS}_{\mathrm{out}}\right)$ of the nanoring (Figure 6).

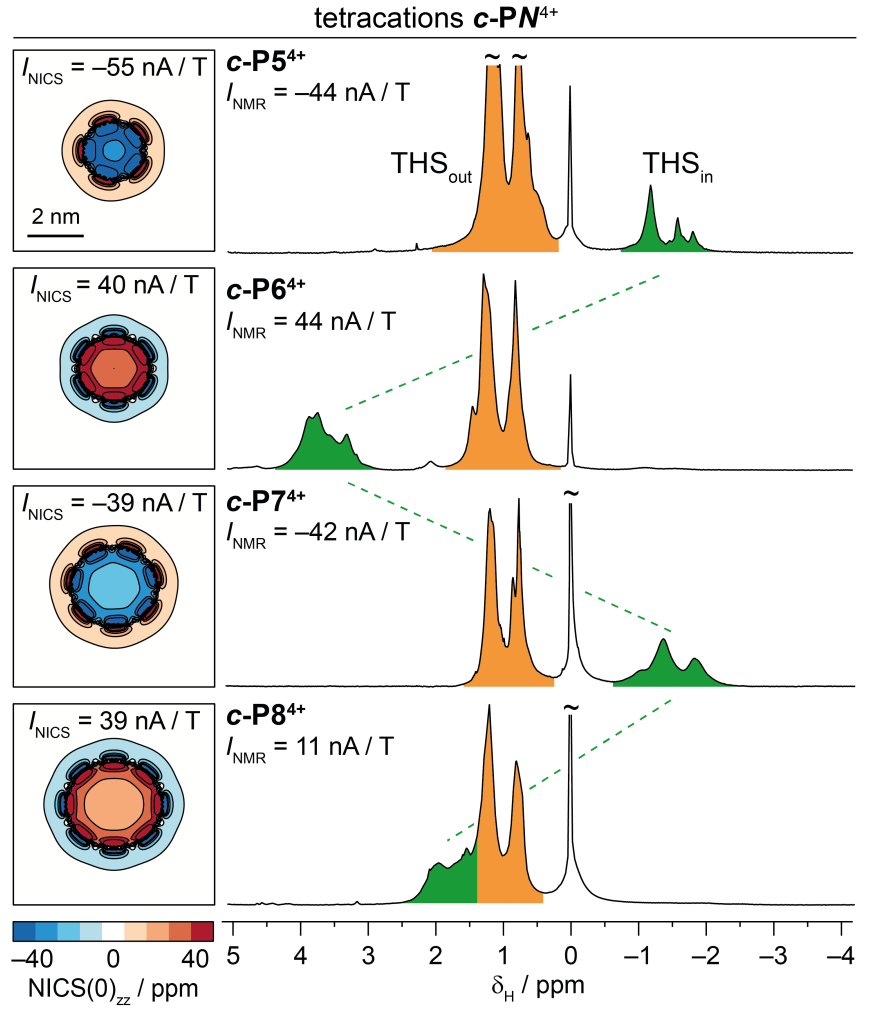

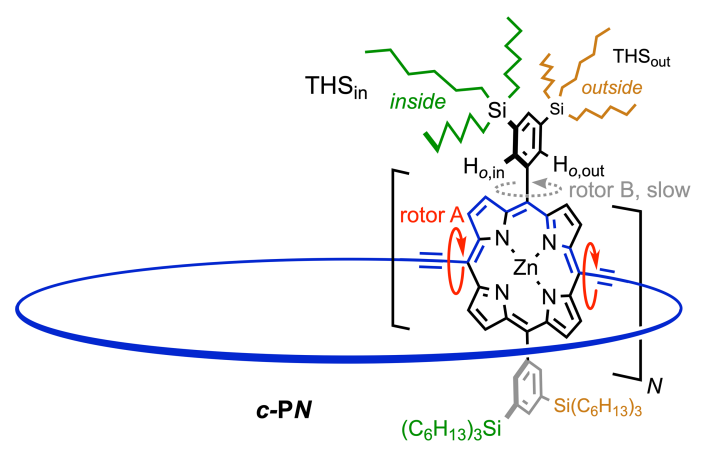

Figure 6. 3-D representation of $\boldsymbol{c}-\mathbf{P} \boldsymbol{N}$ showing the two nonequivalent THS groups pointing either inside or outside the macrocycle. The two THS environments can be exchanged by rotation of a porphyrin unit (rotor A), which has a much lower barrier than rotation of the aryl group (rotor B).

The oxidation of nanorings $\boldsymbol{c}-\mathbf{P} N(N=5-8)$ and $\boldsymbol{c}$-P6(t) was carried out by titration with thianthrenium hexafluoroantimonate $\left(\mathrm{Thn}^{+} \mathrm{SbF}_{6}{ }^{-}\right)$, as reported previously. ${ }^{11}$ This singleelectron oxidant has a suitable reduction potential $(0.86 \mathrm{~V} v s$. $\mathrm{Fc} / \mathrm{Fc}^{+}$) to prepare any oxidation state in the range $Q=1$ to $N$ (i.e. up to one positive charge per porphyrin). ${ }^{1} \mathrm{H}$ NMR spectra of tetra- and hexacations of $\boldsymbol{c}-\mathbf{P} \boldsymbol{N}(N=5-8)$, together with calculated 2D maps of the nucleus-independent chemical shifts (NICS) indicating the predicted global (anti)aromaticity, as summarized in Figure 7. Each bis(ethynyl)porphyrin unit contributes $14 \pi$ electrons to the overall $\pi$-conjugation path, giving a total Hückel electron count of $14 N-Q$. All the spectra of $c-\mathbf{P} N^{4+}$ and $c-\mathbf{P} N^{6+}$ display evidence for the ring currents expected from the Hückel rule.

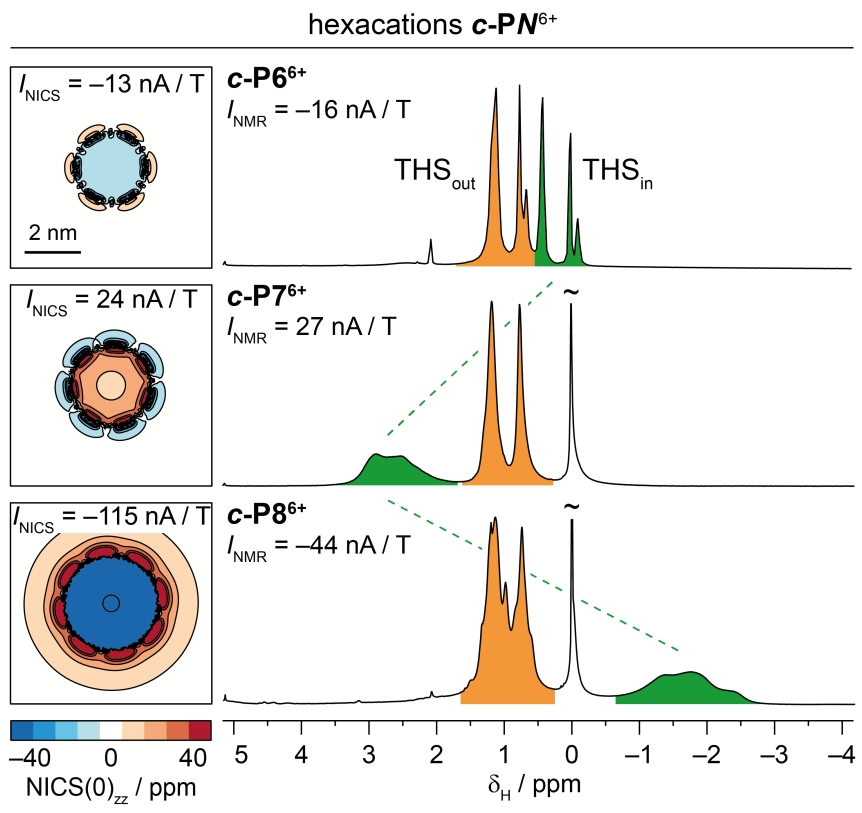

Figure 7. NICS $(0)_{z z}$ (left panels, LC- $\omega$ hPBE $\left.(\omega=0.1) / 6-31 \mathrm{G}^{*}\right)$ and ${ }^{1} \mathrm{H}$ NMR spectra $\left(500 \mathrm{MHz}, \mathrm{CD}_{2} \mathrm{Cl}_{2}\right)($ right panels) of $\boldsymbol{c}$-P5-8 tetracations (left) and $\boldsymbol{c}$-P6-8 hexacations (right). $I_{\mathrm{NICS}}$ and $I_{\mathrm{NMR}}$ are estimates of the global ring current from fitting a current loop model to the NICS and NMR data (see SI Section 6.5.2 for details). 
The ${ }^{1} \mathrm{H}$ NMR spectra of these cationic nanorings are broad, probably due to conformational exchange, and only the THS signals (which comprise $92 \%$ of the hydrogens) are identifiable. Under the conditions of these experiments $\left(\mathrm{CD}_{2} \mathrm{Cl}_{2},-60\right.$ to $-30{ }^{\circ} \mathrm{C}, 500 \mathrm{MHz}{ }^{1} \mathrm{H}$ NMR), the rotation of the porphyrin units and the accompanying exchange of the THS $\mathrm{in}_{\text {in }}$ and $\mathrm{THS}_{\text {out }}$ environments proceeds slowly on the NMR timescale. Odd nanoring tetracations $\left(\boldsymbol{c}-\mathbf{P 5}^{4+}\right.$ and $\left.\boldsymbol{c}-\mathbf{P} 7^{4+}\right)$ and even nanoring hexacation $\left(c-\mathbf{P F}^{6+}\right.$ and $c$ - $\left.\mathbf{P 8}^{6+}\right)$ have diatropic ring currents, resulting in shielded $\mathrm{THS}_{\mathrm{in}}$ resonances at 0 to $-2 \mathrm{ppm}$. In contrast, even nanoring tetracations $\left(\boldsymbol{c}-\mathbf{P 6}^{4+}\right.$ and $\boldsymbol{c}$-P8 $\left.\mathbf{8}^{4+}\right)$ and the odd nanoring hexacation $\left(c-\mathbf{P} 7^{6+}\right)$ have paratropic ring currents, resulting in deshielded $\mathrm{THS}_{\text {in }}$ resonances at 2-4 ppm (Figure 7). All of the observed ring currents are well reproduced by DFT (LC- $\omega$ hPBE $\left.(\omega=0.1) / 6-31 \mathrm{G}^{*}\right)$ NICS calculations. The magnitudes of the calculated and observed ring currents ( $I_{\mathrm{NICS}}$ and $\left.I_{\mathrm{NMR}}\right)$ were estimated using a current-loop model to simulate the shielding, giving the values $(\mathrm{nA} / \mathrm{T})$ listed in Figure 7.

The assignments of the $\mathrm{THS}_{\text {in }}$ resonances in Figure 7 might appear speculative, but they are based on two lines of reasoning: Firstly, the spectra of these template-free nanoring cations are very similar to those of the corresponding template-bound nanorings, in which the $\mathrm{THS}_{\text {in }}$ signals have been unambiguously assigned by the observation of NOEs to the template (see SI Section 4.3). Secondly, the THS signal that is most shielded or deshielded by the global ring current is always expected to be $\mathrm{THS}_{\mathrm{in}}$, because these internal sidechains experience the largest induced magnetic field, whereas $\mathrm{THS}_{\text {out }}$ signals are expected to remain at around $0.5-1.5 \mathrm{ppm}$. This argument is based on mapping the area occupied by the $\mathrm{THS}_{\text {in }}$ and THS $_{\text {out }}$ chains during molecular dynamics runs. For example, in the case of $\boldsymbol{c}$-P6, trajectories of both THS groups were mapped at a simulated temperature of $-40{ }^{\circ} \mathrm{C}$ for $60 \mathrm{ps}$, while taking a snap shot every $1 \mathrm{ps}(\mathrm{MM}+$ forcefield; for details see SI Section 6.6). By approximating the barrel-shaped $c$-P6 to cylindrical symmetry (with the nanoring center at $r=0, z=0$ ) and collapsing the angular coordinates onto a plane, the area occupied by THS hydrogens can be displayed as a 2D graph. The population of individual positions is shown as a 2D histogram in Figure 8a; for clarity this graph only shows the positions for $\mathrm{Si}-\mathrm{CH}_{2}-$ protons, but a similar analysis has been carried out for all the THS protons. The overlay with lines of forces, approximating the induced magnetic field from the nanoring, allows a comparison of the expected relative influence of the global ring current on $\mathrm{THS}_{\text {in }}$ and THS $\mathrm{Sut}_{\text {out }}$ The volume of space populated by $\mathrm{THS}_{\text {out }}$ is mainly located within a cone of very low induced magnetic field near $\Delta \delta=0$. On the contrary, a significant fraction of the $\mathrm{THS}_{\text {in }}$ protons is found in areas strongly influenced by the ring current. The induced magnetic field experienced by the whole THS units can be visualized with a $1 \mathrm{D}$ histogram (Figure $8 \mathrm{~b}$ ). The average shifts $\left(\Delta \delta=-0.052\right.$ and $+0.006 \mathrm{ppm} \mathrm{nA}^{-1} \mathrm{~T}$ for $\mathrm{THS}_{\text {in }}$ and $\mathrm{THS}_{\text {out }}$, respectively) predict that $\mathrm{THS}_{\text {in }}$ is approximately ten times more sensitive to the ring current. This agrees with the experimental observations: THS $_{\text {in }}$ is always found to be shifted by the global ring current, whereas $\mathrm{THS}_{\text {out }}$ remains almost unshifted. ${ }^{11}$
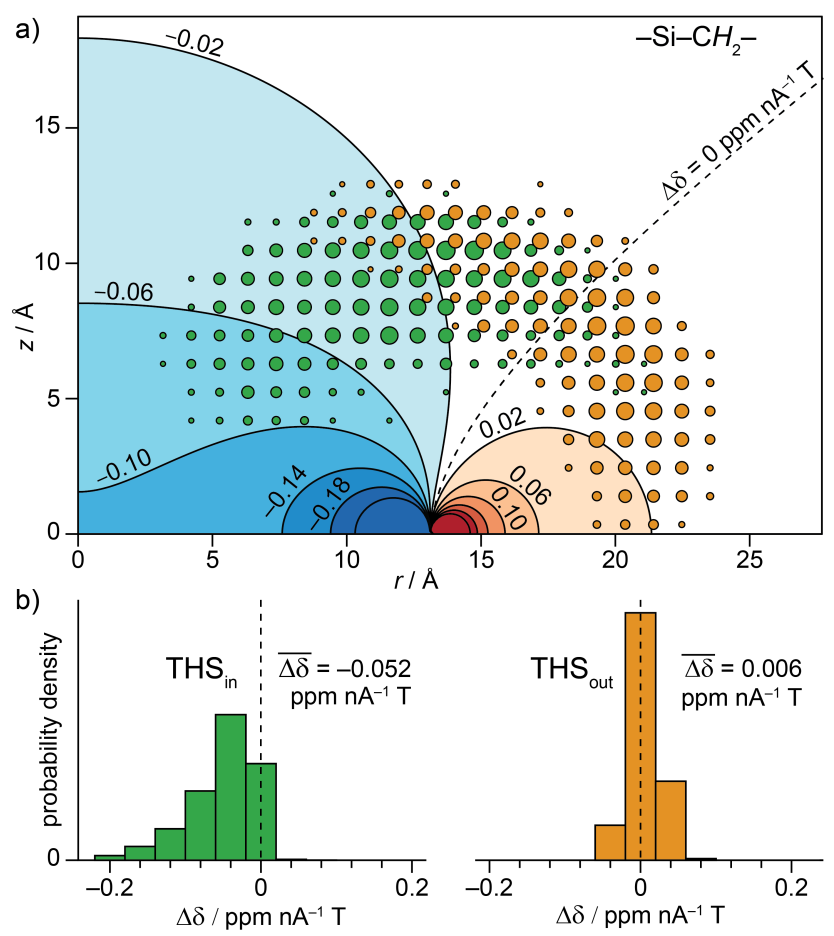

Figure 8. a) Map of magnetic field induced by a current loop of radius $12.3 \AA$, expressed as relative chemical shift in ppm induced

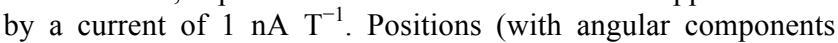
collapsed onto the vertical plane) populated by $\mathrm{Si}-\mathrm{CH}_{2}-$ hydrogen atoms of $\boldsymbol{c}$-P6 of both $\mathrm{THS}_{\text {in }}$ (green) and $\mathrm{THS}_{\text {out }}$ (orange) are overlaid with a magnetic field map as a $2 \mathrm{D}$ histogram with a bin size of $1 \times 1 \AA$; the sizes of the points scale with the probability of populating each area of space. b) $1 \mathrm{D}$ histograms of the induced magnetic field experienced by $\mathrm{THS}_{\mathrm{in}}$ (left) and $\mathrm{THS}_{\text {out }}$ (right) unveil a dominant effect on the $\mathrm{THS}_{\text {in }}$ relative to $\mathrm{THS}_{\text {out }}$. The values in the top-right corner are the overall average of the expected chemical shift of the THS units per $1 \mathrm{nA} \mathrm{T}^{-1}$ ring current.

\section{Rotational Barriers}

In this section, we show how rotational barriers in (anti)aromatic $\boldsymbol{c}-\mathbf{P} N^{\boldsymbol{Q}^{+}}$cations provide insights into the ASEs in these macrocycles, but first we consider the rotational barriers in the neutral $\boldsymbol{c}-\mathbf{P} \boldsymbol{N}$ rings $(N=5-8)$. The energy barrier for rotating one porphyrin unit in a nanoring (rotor A), was estimated from the rate of exchange between the ortho-aromatic protons $\mathrm{H}_{o \text {,in }}$ and $\mathrm{H}_{o \text {,out }}$ (Figure 6). The alternative exchange pathway, via rotation of the 3,5-bis(trihexylsilyl)phenyl group (rotor B), does not compete with this process as it has a substantially higher barrier $\left(79 \mathrm{~kJ} / \mathrm{mol}\right.$ in $\boldsymbol{c}$-P6.T6). ${ }^{11 \mathrm{~b}}$ At low temperate $(174 \mathrm{~K})$, the ${ }^{1} \mathrm{H}$ NMR spectra of $\boldsymbol{c}-\mathbf{P} \boldsymbol{N}$ nanorings $(N$ $=5-7)$ in $d_{8}$-THF show resolved signals for $\mathrm{H}_{o \text {,in }}$ and $\mathrm{H}_{o \text {,out }}$ because the exchange process is slow on the NMR timescale. The $\mathrm{H}_{o \text {,in }}$ and $\mathrm{H}_{o \text {,out }}$ signals coalesce as the temperature is increased, and coalescence temperatures were used to estimate exchange rates and free-energy barriers, using the Eyring equation. We were unable to measure the exchange rate in $c$ P8 because exchange is too fast; the $\mathrm{H}_{o}$ peak broadens on cooling to $174 \mathrm{~K}$, but does not split into two signals. The barriers to porphyrin rotation (Table $2, Q=0$ ) decrease as the rings get larger from $\boldsymbol{c}$-P5 to $\boldsymbol{c}$-P8, as expected from the decreasing ring strain. Even in $\boldsymbol{c - P 7}$, the rotational barrier (34.6 $\mathrm{kJ} \mathrm{mol}^{-1}$ ) is much higher than in a linear butadiyne-linked porphyrin dimer (ca. $\left.5 \mathrm{~kJ} \mathrm{~mol}^{-1}\right){ }^{41}$ reflecting the strain in the nanorings. 
Table 2. Experimental porphyrin rotation exchange rates and energy barriers.

\begin{tabular}{|c|c|c|c|c|}
\hline$Q$ & $c-\mathrm{P} N^{Q^{+}}$ & $T$ & $\boldsymbol{k}\left(\mathrm{s}^{-1}\right)$ & $\Delta G^{\ddagger}\left(\mathrm{kJ} \mathrm{mol}^{-1}\right)$ \\
\hline \multirow[t]{4}{*}{0} & $c-\mathrm{P5}$ & $-37^{\circ} \mathrm{C}$ & $120^{\mathrm{a}}$ & $48.0 \pm 1.0$ \\
\hline & $c-\mathrm{P6}$ & $-70^{\circ} \mathrm{C}$ & $578^{\mathrm{a}, \mathrm{b}}$ & $38.0 \pm 0.3$ \\
\hline & $c-\mathbf{P 6}(\mathrm{t})$ & $-91^{\circ} \mathrm{C}$ & $262^{\mathrm{a}}$ & $35.6 \pm 1.0$ \\
\hline & $c-\mathrm{P} 7$ & $-93^{\circ} \mathrm{C}$ & $347^{\mathrm{a}}$ & $34.6 \pm 1.0$ \\
\hline 2 & $c-\mathrm{P6}^{2+}$ & $-60^{\circ} \mathrm{C}$ & $59.5 \pm 7.5^{\mathrm{c}}$ & $44.3 \pm 1.0$ \\
\hline \multirow[t]{3}{*}{4} & $c-\mathrm{P6}^{4+}$ & $-60^{\circ} \mathrm{C}$ & $14.3 \pm 0.4^{\mathrm{c}}$ & $46.9 \pm 0.9$ \\
\hline & $c-\mathrm{P} 6(\mathrm{t})^{4+}$ & $-50^{\circ} \mathrm{C}$ & $9.5 \pm 0.4^{\mathrm{c}}$ & $52.2 \pm 1.3$ \\
\hline & $c-\mathrm{P} 7^{4+}$ & $-60^{\circ} \mathrm{C}$ & $15.4 \pm 0.5^{\mathrm{c}}$ & $46.7 \pm 1.2$ \\
\hline \multirow[t]{4}{*}{6} & $c-\mathrm{P6}^{6+}$ & $-60^{\circ} \mathrm{C}$ & $1.23 \pm 0.02^{\mathrm{c}}$ & $51.2 \pm 0.8$ \\
\hline & $c-\mathrm{P6}(\mathrm{t})^{6+}$ & $-50^{\circ} \mathrm{C}$ & $4.1 \pm 0.2^{\mathrm{c}}$ & $53.8 \pm 1.3$ \\
\hline & $c-\mathrm{P}^{6+}$ & $-60^{\circ} \mathrm{C}$ & $28.9 \pm 0.5^{\mathrm{c}}$ & $45.6 \pm 1.1$ \\
\hline & $c-\mathrm{P8}^{6+}$ & $-65^{\circ} \mathrm{C}$ & $14.6 \pm 0.8^{\mathrm{c}}$ & $45.7 \pm 1.4$ \\
\hline
\end{tabular}

${ }^{\mathrm{a}} k$ from coalescence in $d_{8}$-THF. ${ }^{\mathrm{b}}$ Data from ref. $11 \mathrm{~b} .{ }^{\mathrm{c}} k$ from EXSY in $\mathrm{CD}_{2} \mathrm{Cl}_{2}$. Errors were estimated from an uncertainty in the temperature of $\pm 5 \mathrm{~K}$.

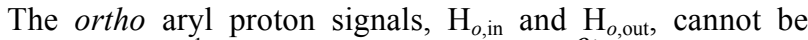
identified in the ${ }^{1} \mathrm{H}$ NMR spectra of the $\boldsymbol{c}-\mathbf{P} \boldsymbol{N}^{\boldsymbol{Q}^{+}}$cations (except in the case of $\boldsymbol{c}-\mathbf{P 6}^{\mathbf{6}}$ ), so rotation of the porphyrin units in these oxidized species was probed through exchange of $\mathrm{THS}_{\text {in }} / \mathrm{THS}_{\text {out }}$ signals. The rate of exchange between these signals can be estimated from their coalescence temperatures, but the broadness of the signals makes this method unreliable. We found that exchange rates can be estimated more accurately by measuring the transfer of magnetization between the $\mathrm{THS}_{\text {in }} / \mathrm{THS}_{\text {out }}$ resonances using exchange spectroscopy (EXSY), at low temperature when exchange is slow on the chemical shift timescale. The ratio of the off-diagonal to ondiagonal signals, $r$, in the 2D EXSY spectrum is related to the rate constant $k$ of the exchange process and the mixing time $\tau_{\text {mix }}$ according to equation (4). ${ }^{42}$

$$
r=\frac{1-e^{-k \tau_{m i x}}}{1+e^{-k \tau_{m i x}}}
$$

A series of 2D EXSY experiments at various mixing times $\left(\tau_{\text {mix }}=5-125 \mathrm{~ms}\right)$ were performed for the tetra- and hexacations of $\boldsymbol{c}$-P6-8 and $\boldsymbol{c}$-P6(t). The ratio $r$ was estimated by integrating the off- and on-diagonal signals related to the $\mathrm{THS}_{\text {in. }}$. Unfortunately, the EXSY spectrum of $\boldsymbol{c}$ - $\mathbf{P 8} \mathbf{8}^{\mathbf{4}}$ could not be used as its low coalescence temperature did not allow accurate measurement of the off-diagonal signal intensity. The evolution of transferred magnetization, plotted as the ratio $r$ against the mixing time $\tau_{\text {mix }}$, and the fit of variable $k$ using equation (4) (Figure 9), gave the exchange rates and barriers listed in Table $2(Q=2-6)$. The barrier heights are plotted against oxidation state, $Q$ in Figure 10a.

The rotation barriers in the $\boldsymbol{c}-\mathbf{P} \boldsymbol{N}^{\boldsymbol{Q}^{+}}$cations $(N=6-8)$ are all much higher than the rotational barriers in the corresponding neutral nanorings $\boldsymbol{c}-\mathbf{P} \boldsymbol{N}$, regardless of whether the nanoring cation is aromatic or antiaromatic (Table 2). The increase in barrier height in the cations must originate form the fact that rotating a porphyrin out of $\pi$-conjugation disrupts charge delocalization. This explains why the ${ }^{1} \mathrm{H}$ NMR spectra of the $c$ $\mathbf{P} N^{\boldsymbol{Q}^{+}}$cations are so similar to those of their template complexes: the geometry is locked by the positive charge, so that a template is not needed to enforce the cylindrical conformation.

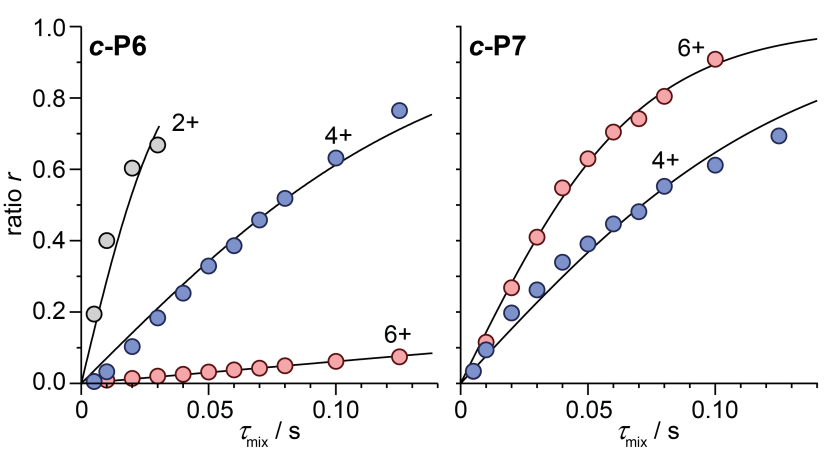

Figure 9. Examples of the ratios of the off-diagonal to ondiagonal $\mathrm{THS}_{\text {in }}$ signal integrals $(r)$ from ${ }^{1} \mathrm{H}-{ }^{1} \mathrm{H}$ EXSY NMR experiments $\left(500 \mathrm{MHz}, \mathrm{CD}_{2} \mathrm{Cl}_{2},-60{ }^{\circ} \mathrm{C}\right)$ at various mixing times $\left(\tau_{\text {mix }}\right)$ for various oxidation states of $\boldsymbol{c}-\mathbf{P 6}$ (left) and $\boldsymbol{c}-\mathbf{P 7}$ (right) fitted to equation (4).
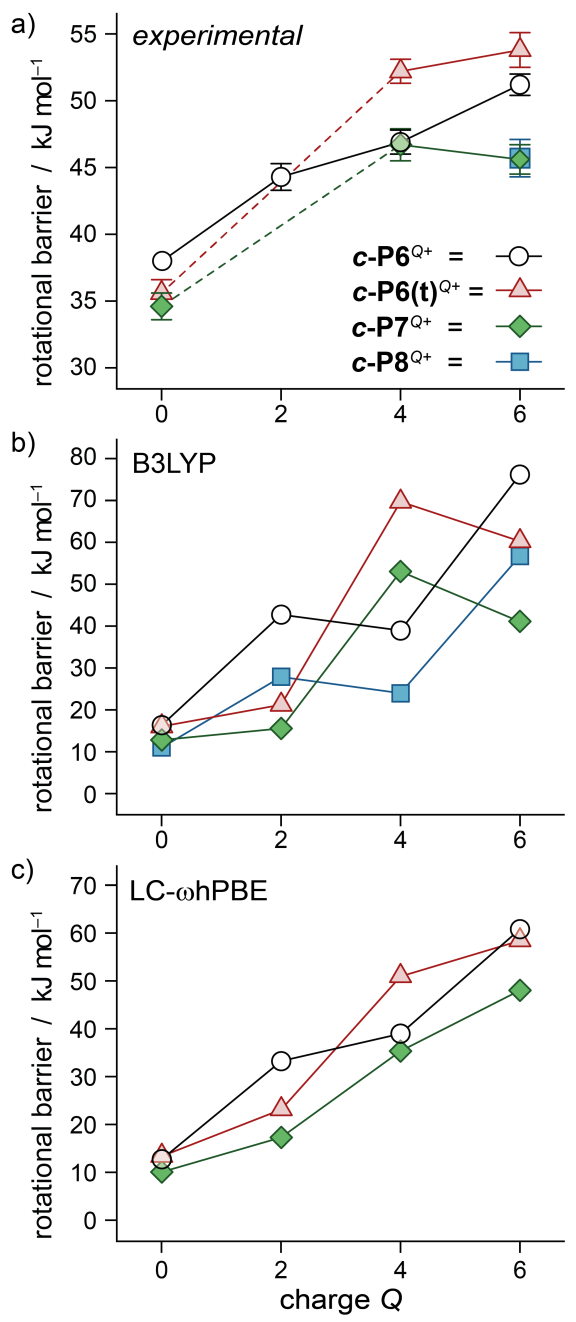

Figure 10. Porphyrin rotational barriers (a) measured experimentally for $\boldsymbol{c}$-P6, $\boldsymbol{c}$-P6(t) and $\boldsymbol{c}$-P7 at various oxidation states (data from Table 2), and calculated rotational barriers $c$-P6, $c$-P6(t), $c$ P7 and $\boldsymbol{c}$-P8 using (b) B3LYP and (c) LC- $\omega \mathrm{hPBE}(\omega=0.1)$ functionals, both with ZPE correction.

Comparison of the rates of magnetization transfer in the $c$ $\mathbf{P 6}^{\boldsymbol{Q}^{+}}$and $\boldsymbol{c}-\mathbf{P} 7^{\boldsymbol{Q}^{+}}$cations (Figure 9 ) reveals a surprising difference: in $\boldsymbol{c}-\mathbf{P 6}^{\mathbf{Q}^{+}}$, the rates of porphyrin rotation decrease steeply with increasing charge, becoming very slow in the aromatic $c-\mathbf{P 6}^{6+}$ cation; in contrast, the antiaromatic $\boldsymbol{c}-\mathbf{P 7}^{\mathbf{6}}{ }^{+}$exhibits 
faster rotation than $\boldsymbol{c}-\mathbf{P} \mathbf{7}^{\mathbf{4}}$. This is a clear sign that ASE influences the barrier height. In general, there is a steady increase in the barrier height with charge (approx. $2 \mathrm{~kJ} \mathrm{~mol}^{-1}$ per unit charge), driven by charge delocalization (Figure 10a). The aromatic states, $\boldsymbol{c}-\mathbf{P 6} \mathbf{6}^{2+}, \boldsymbol{c}-\mathbf{P 6} \mathbf{6}^{6+}, \boldsymbol{c - P 6}(\mathbf{t})^{4+}$ and $\boldsymbol{c}-\mathbf{P} 7^{4+}$, show a deviation to higher barriers relative to the antiaromatic states, $c-\mathbf{P 6}^{4+}, c-\mathbf{P 7}^{6+}$ and $c-\mathbf{P 6}(\mathbf{t})^{6+}$. The deviations from a linear rise in rotational barrier indicates that the ASE is about $1-3 \mathrm{~kJ}$ $\mathrm{mol}^{-1}$ (Table S8), which is a similar magnitude to the ASE deduced from redox potentials.

DFT was used to predict the rotational barriers, by calculating the energies of transition states in which a porphyrin unit is rotated into the plane of the nanoring. The geometry of a typical transition state is compared with the ground state conformation in Figure 11. These calculations were carried out for the neutral, $2+, 4+$ and $6+$ oxidation states of $c$-P6, $c$-P6(t), $c$ P7 and $c$-P8, using both the B3LYP and LC- $\omega$ hPBE $(\omega=0.1)$ functionals, to give the barriers plotted in Figures $10 \mathrm{~b}$ and $10 \mathrm{c}$, respectively, reproducing the experimentally observed rise in barrier height with increasing oxidation state.

The transition state geometries were identified by scanning a dihedral angle between the whole nanoring and that of the individual porphyrin unit being rotated. Geometries with the highest energy have dihedral angles near $0^{\circ}$. These geometries were evaluated as transition states by performing harmonic vibrational frequency calculations unveiling one imaginary frequency. Translational motion of the nuclei along this mode corresponded to rotation of the porphyrin unit. Energies of both ground and transition states were corrected for ZPE, although in most cases the effect of this correction was negligible (see SI Section 6.3).

Clear oscillations, in line with the $[4 n+2] /[4 n]$ count, show that ASE contributes towards the energy barrier (Figures $10 \mathrm{~b}, \mathrm{c})$. The deviation from linearity in these plots indicate that the magnitude of the ASE is $7-16 \mathrm{~kJ} \mathrm{~mol}^{-1}$ for the B3LYP functional, and $4-11 \mathrm{~kJ} \mathrm{~mol}^{-1}$ for LC- $\omega \mathrm{hPBE}$ (Figure 10b,c and Table S22). Thus the magnitude of the ASE estimated from these oscillations in the energy barrier matches well with that estimated from the homodesmotic reaction shown in Figure 4 .

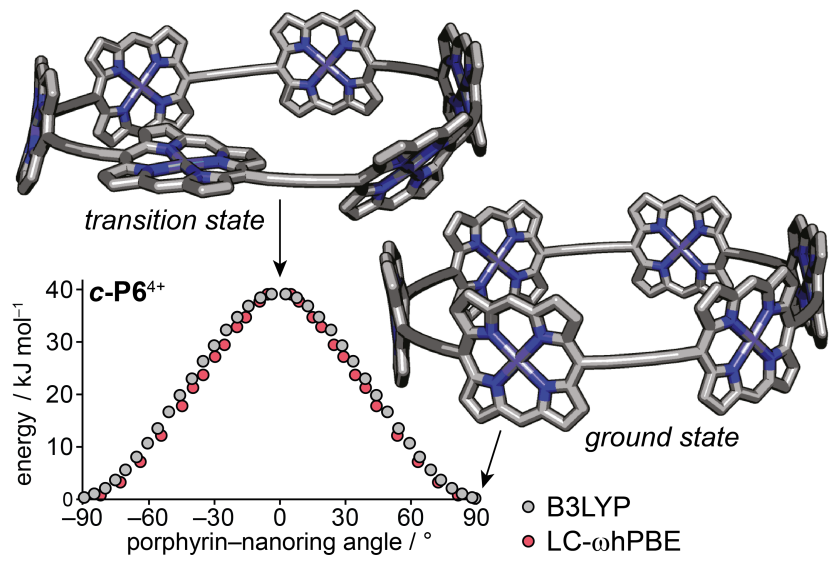

Figure 11. Example geometries of the ground state and transition state during the porphyrin rotation $\boldsymbol{c}-\mathbf{P 6}^{4+}$ calculated using the $\mathrm{B} 3 \mathrm{LYP} / 6-31 \mathrm{G}^{*}$ functional, and energy profiles from both B3LYP/6-31G* and LC- $\omega$ hPBE methods.

\section{Conclusions}

The main conclusion form this study is that porphyrin nanoring cations with Hückel electron counts of 76-108 $\pi$ electrons display ASEs with magnitudes in the range $1-5 \mathrm{~kJ}$ $\mathrm{mol}^{-1}$. Two different types of experimental data lead to this conclusion: (a) oxidation potentials and (b) barriers to conformational exchange. In both cases, evidence for ASE is provided by oscillations in the energy when plotted as a function of charge state $Q$, as the electron count alternates between [4n] and $[4 n+2]$. There is also clear theoretical evidence for ASE in these systems, from calculated oxidation potentials and calculated conformational energy barriers. The computational results mirror the experimental findings, although the magnitudes of the predicted ASEs is larger than that found experimentally. The ASEs predicted using the B3LYP functional (6$16 \mathrm{~kJ} \mathrm{~mol}^{-1}$ ) are larger than those calculated using LC- $\omega \mathrm{hPBE}$ $\left(1-11 \mathrm{~kJ} \mathrm{~mol}^{-1}\right)$, which is consistent with the observation that B3LYP tends to exaggerate delocalization and global aromaticity. ${ }^{36,38,39}$ The estimated ring currents in the porphyrin nanoring cations deduced by fitting the observed ${ }^{1} \mathrm{H}$ NMR shifts to a current loop model $\left(I_{\mathrm{NMR}}\right.$, Figure 7$)$, match well with the predicted ring currents from the LC- $\omega$ hPBE NICS calculations $\left(I_{\mathrm{NICS}}\right.$, Figure 7$)$, but they do not match with the ring currents from B3LYP NICS calculations (Table S27), confirming that the LC- $\omega$ hPBE $(\omega=0.1)$ functional provides a better description of these systems.

At the start of this study, we thought it would be impossible to study antiaromatic porphyrin nanoring cations without a central template to lock the geometry, because we anticipated that, in the absence of a bound template, the porphyrins would twist out of conjugation to avoid antiaromaticity. This prediction turned out to be wrong. In reality, the presence of a positive charge tends to lock the nanorings into cylindrical geometries, regardless of whether they are aromatic or antiaromatic. A similar effect arises in doped linear $\pi$-conjugated oligomers, where the presence of positive charge forces the whole $\pi$ system into a planar conformation. ${ }^{38,43,44}$ In the cationic porphyrin nanorings, the high barrier to conformational exchange resulting from the favorability of charge delocalization is modulated by the ASE. The [N]annulenes have more complicated conformational landscapes, however, the plot of barrier vs. $N$ (Figure 2) shows a clear alternation, suggesting that ASE modulates the barrier height in $[N]$ annulenes in a similar way. This alternation in barrier height, from experimental NMR data, suggests that the ASE of [18]annulene is about $11 \mathrm{~kJ}$ $\mathrm{mol}^{-1}$ (compared with $36.9 \mathrm{~kJ} \mathrm{~mol}^{-1}$ from DFT calculations of hyperhomodesmotic reactions), which is significantly lower than previously reported estimates. ${ }^{15,19,20-23,25}$

To the best of our knowledge, this is the first study to provide experimental evidence for ASE in systems with Hückel electron counts greater than 18. Our results show that aromaticity has a small, but measurable, effect on the stability of large $\pi$-conjugated macrocycles. We demonstrate the advantage of estimating ASEs by comparing the energies of closely related aromatic and antiaromatic systems, which differ by two $\pi$-electrons, either by changing the oxidation sate by $\Delta Q=2$ or by changing the covalent framework, e.g. $c$-P6 vs. $\boldsymbol{c}$-P6(t). This avoids comparison with a hypothetical nonaromatic version of the molecule, which has often been an obstacle to previous work on estimating ASEs.

\section{ASSOCIATED CONTENT}




\section{Supporting Information}

The supporting information is available free of charge on the ACS publication website at DOI: $\mathrm{xxx}$

Synthetic procedures, NMR assignments, NMR oxidation titrations, NMR exchange experiments, computational details (PDF)

DFT optimized structures of $\boldsymbol{c}-\mathbf{P} \boldsymbol{N}$ and $\boldsymbol{c}-\mathbf{P} \boldsymbol{N}(\mathbf{t}), N=5-8$, in various oxidation states $(0,2+, 4+$ and $6+)$ from B3LYP and LCwhPBE functionals (XYZ)

\section{AUTHOR INFORMATION}

\section{Corresponding Author}

Harry L. Anderson - Department of Chemistry, University of Oxford, Chemistry Research Laboratory, Oxford OX1 3TA, United Kingdom; orcid.org/0000-0002-1801-8132;

Email: harry.anderson@chem.ox.ac.uk

\section{Authors}

Michael Jirasek - Department of Chemistry, University of Oxford, Chemistry Research Laboratory, Oxford OX1 3TA, United Kingdom; orcid.org/0000-0002-4630-6457

Michel Rickhaus - Department of Chemistry, University of Oxford, Chemistry Research Laboratory, Oxford OX1 3TA, United Kingdom; orcid.org/0000-0002-6107-2310

Lara Tejerina - Department of Chemistry, University of Oxford, Chemistry Research Laboratory, Oxford OX1 3TA, United Kingdom; orcid.org/0000-0003-1000-6310

\section{Author Contributions}

The manuscript was written through contributions of all authors. All authors have given approval to the final version of the manuscript.

\section{Notes}

The authors declare no competing financial interest.

\section{ACKNOWLEDGMENTS}

We thank the ERC (grant 320969), EPSRC (EP/M016110/1), the European Union's Horizon 2020 research and innovation programme (Marie Sklodowska-Curie grant SYNCHRONICS 643238) and the Swiss National Science Foundation (P2BSP2 168919) for funding, the EPSRC UK National Mass Spectrometry Facility at Swansea University for mass spectra and the University of Oxford Advanced Research Computing Service (ARC) for support. M.J. thanks Oxford University for a Scatcherd European Scholarship.

\section{REFERENCES}

1. (a) Schleyer, P. v. R.; Jiao, H. What is Aromaticity? Pure Appl. Chem. 1996, 68, 209-218. (b) Krygowski, T. M.; Cyrañski, M. K.; Czarnocki, Z.; Häfelinger, G.; Katritzky, A. R. Aromaticity: a Theoretical Concept of Immense Practical Importance. Tetrahedron 2000, 56, 1783-1796. (c) Gleiter, R.; Haberhauer, G. Aromaticity and Other Conjugation Effects; Wiley-WCH: Weinheim, Germany, 2012. (d) Mirkin, V. I.; Glukhovtsev, M. N.; Simkin, B. Ya. Aromaticity. Electronic and Structural Aspects. Wiley 1994.

2. Cyrañski, M. K. Energetic Aspects of Cyclic Pi-Electron Delocalization: Evaluation of the Methods of Estimating Aromatic Stabilization Energies. Chem. Rev. 2005, 105, 3773-3811.

3. (a) Chen, Z.; Wannere, C. S.; Corminboeuf, C.; Puchta, R.; Schleyer, P. v. R. Nucleus-Independent Chemical Shifts (NICS) as an Aromaticity Criterion. Chem. Rev. 2005, 105, 3842-3888. (b) Gershoni-Poranne, R.; Stanger, A. Magnetic criteria of aromaticity. Chem. Soc. Rev. 2015, 44, 6597-6615.
4. Slayden, S. W.; Liebman, J. F. The Energetics of Aromatic Hydrocarbons: An Experimental Thermochemical Perspective. Chem. Rev. 2001, 101, 1541-1566.

5. (a) Soya, T.; Mori, H.; Osuka, A. Quadruply Twisted HückelAromatic Dodecaphyrin. Angew. Chem. Int. Ed. 2018, 57, 1588215886. (b) Tanaka, T.; Osuka, A. Chemistry of meso-Aryl-Substituted Expanded Porphyrins: Aromaticity and Molecular Twist. Chem. Rev. 2017, 117, 2584-2640.

6. (a) Cha, W.-Y.; Kim, T.; Ghosh, A.; Zhang, Z.; Ke, X.-S.; Ali, R.; Lynch, V. M.; Jung, J.; Kim, W.; Lee, S.; Fukuzumi, S.; Park, J. S.; Sessler, J. L.; Chandrashekar, T. K.; Kim, D. Bicyclic Baird-type aromaticity. Nat. Chem. 2017, 9, 1243-1248. (b) Ke, X.-S.; Kim, T.; He, Q.; Lynch, V. M.; Kim, D.; Sessler, J. L. Three-Dimensional Fully Conjugated Carbaporphyrin Cage. J. Am. Chem. Soc. 2018, 140, $16455-16459$.

7. (a) Ni, Y.; Gopalakrishna, T. Y.; Phan, H.; Kim, T.; Herng, T. S.; Han, Y.; Tao, T.; Ding, J.; Kim, D.; Wu, J. 3D global aromaticity in a fully conjugated diradicaloid cage at different oxidation states. Nat. Chem. 2020, 12, 242-248. (b) Ren, L.; Gopalakrishna, T. Y.; Park, I.-H.; Han, Y.; Wu, J. Porphyrin/Quinoidal-Bithiophene-Based Macrocycles and Their Dications: Template-Free Synthesis and Global Aromaticity. Angew. Chem. Int. Ed. 2020, 59, 2230-2234. (c) Li, Z.; Gopalakrishna, T. Y.; Han, Y.; Gu, Y.; Yuan, L.; Zeng, W.; Casanova, D.; Wu, J. [6]Cyclo-para-phenylmethine: An Analog of Benzene Showing Global Aromaticity and Open-Shell Diradical Character. J. Am. Chem. Soc. 2019, 141, 16266-16270. (d) Liu, C.; Sandoval-Salinas, M. E.; Hong, Y.; Gopalakrishna, T. Y.; Phan, H.; Aratani, N. Herng, T. S.; Ding, J.; Yamada, H.; Kim, D.; Casanova, D.; Wu, J. Macrocyclic Polyradicaloids with Unusual Super-ring Structure and Global Aromaticity. Chem. 2018, 4, 1586-1595. (e) Liu, C.; Ni, Y.; Lu, X.; Li, G.; Wu, J. Global Aromaticity in Macrocyclic Polyradicaloids: Hückel's Rule or Baird's Rule? Acc. Chem. Res. 2019, 52, 2309-2321.

8. Majewski, M. A.; Stepien, M. Bowls, Hoops, and Saddles: Synthetic Approaches to Curved Aromatic Molecules. Angew. Chem. Int. Ed. 2019, 58, 86-116.

9. Naulet, G.; Sturm, L.; Robert, A.; Dechambenoit, P.; Röhricht, F.; Herges, R.; Bock, H.; Durola, F. Cyclic tris-[5]helicenes with single and triple twisted Möbius topologies and Möbius aromaticity. Chem. Sci. 2018, 9, 8930-8936.

10. Szyszko, B.; Latos-Grazynski, L. Expanded Carbaporphyrinoids. Angew. Chem. Int. Ed. 2020, 59, 16874-16901.

11. (a) Peeks, M. D.; Claridge, T. D. W.; Anderson, H. L. Aromatic and Antiaromatic Ring Currents in a Molecular Nanoring. Nature 2017, 541, 200-203. (b) Peeks, M. D.; Jirasek, M.; Claridge, T. D. W.; Anderson, H. L. Global Aromaticity and Antiaromaticity in Porphyrin Nanoring Anions. Angew. Chem. Int. Ed. 2019, 58, 1571715720. (c) Rickhaus, M.; Jirasek, M.; Tejerina, L.; Gotfredsen, H.; Peeks, M. D.; Haver, R.; Jiang, H.-W.; Claridge, T. D. W.; Anderson, H. L. Global Aromaticity at the Nanoscale. Nat. Chem. 2020, 12, 236-241. (d) Kopp, S. M.; Gotfredsen, H.; Deng, J.-R.; Claridge, T. D. W.; Anderson, H. L. Global Aromaticity in a Partially Fused 8Porphyrin Nanoring. J. Am. Chem. Soc. 2020, 142, 19393-19401.

12. (a) Lim, J. M.; Shin, J.-Y.; Tanaka, Y.; Saito, S.; Osuka, A.; Kim, D. Protonated $[4 n] \pi$ and $[4 n+2] \pi$ Octaphyrins Choose Their Möbius/Hückel Aromatic Topology. J. Am. Chem. Soc. 2010, 132, 3105-3114. (b) Kim, K. S.; Yoon, Z. S.; Butler Ricks, A.; Shin, J.-Y.; Mori, S.; Sankar, J.; Saito, S.; Jung, Y. M.; Wasielewski, M. R.; Osuka, A.; Kim, D. Temperature-Dependent Conformational Change of meso-Hexakis(pentafluorophenyl) [28]Hexaphyrins(1.1.1.1.1.1) into Möbius Structures. J. Phys. Chem. A 2009, 113, 4498-4506.

13. (a) Aihara, J.; Horikawa, T. Graph-theoretical Formula for Ring Currents Induced in a Polycyclic Conjugated System. Bull. Chem. Soc. Jpn. 1983, 56, 1853-1854. (b) Gomes, J. A. N. F.; Mallion, R. B. Aromaticity and Ring Currents. Chem. Rev. 2001, 101, 1349-1383.

14. Casademont-Reig, I.; Ramos-Cordoba, E.; Torrent-Sucarrat, M.; Matito, E. How do the Hückel and Baird Rules Fade away in Annulenes? Molecules 2020, 25, 711.

15. Choi, C. H.; Kertesz, M. Bond length alternation and aromaticity in large annulenes. J. Chem. Phys. 1998, 108, 6681-6688. 
16. (a) Dewar, M. J. S.; de Llano, C. Ground States of Conjugated Molecules. XI. Improved Treatment of Hydrocarbons. J. Am. Chem. Soc. 1969, 91, 789-795. (b) Schaad, L. J.; Andes Hess, Jr., B. Dewar Resonance Energy. Chem. Rev. 2001, 101, 1465-1476.

17. (a) Wheeler, S. E. Homodesmotic Reactions for Thermochemistry. WIREs Comput. Mol. Sci. 2012, 2, 204-220. (b) Wheeler, S. E.; Houk, K. N.; Schleyer, P. v. R.; Allen, W. D. A Hierarchy of Homodesmotic Reactions for Thermochemistry. J. Am. Chem. Soc. 2009, $131,2547-2560$

18. Pedley, J. B.; Naylor R. D.; Kirby, S. P. Thermodynamical Data of Organic Compounds; Chapman and Hall: London, U.K., 1986.

19. Beezer, A. E.; Mortimer, C. T.; Springall, H. D.; Sondheimer, F.; Wolovsky, R. The Heat of Combustion of Cyclo-octadecanonaene ([18]Annulene). J. Chem. Soc. 1965, 216-220.

20. Oth, J. F. M.; Bünzli, J.-C.; de Julien de Zélicourt, Y. The Stabilization Energy of [18]Annulene. A Thermochemical Determination. Helv. Chim. Acta 1974, 57, 2276-2288.

21. Oth, J. F. M.; Gilles, J.-M. Elucidation, by Scanning Microcalorimetry, of the Detailed Mechanism of the Thermal Rearrangement of [18]Annulene into Benzene and 1,2-Benzo-1,3,7-cyclooctatriene. Determination and Interpretation of the Thermochemical and Kinetic Parameters of the Three Consecutive Reactions Implicated. J. Phys. Chem. A 2000, 104, 7980-7994.

22. Baldridge, K. K.; Siegel, J. S. Ab Initio Density Functional vs Hartree Fock Predictions for the Structure of [18] Annulene: Evidence for Bond Localization and Diminished Ring Currents in Bicycloannelated [18]Annulenes. Angew. Chem. Int. Ed. Engl. 1997, 36, 745748

23. Wannere, C. S.; Schleyer, P. von R. How Aromatic Are Large $(4 n+2) \pi$ Annulenes? Org. Lett. 2003, 5, 865-868.

24. Wannere, C. S.; Moran, D.; Allinger, N. L.; Hess, Jr., B. A.; Schaad, L. J.; Schleyer, P. von R. On the Stability of Large [4n]Annulenes. Org. Lett. 2003, 5, 2983-2986.

25. Gilles, J.-M.; Oth, J. F. M.; Sondheimer, F.; Woo, E. P. Unsaturated Macrocyclic Compounds. Part LXXXIII. A Quantitative Study of the Conformational Mobility of [18]Annulene. J. Chem. Soc. B 1971, 2177-2186.

26. Oth and coworkers estimated the ASE of [18]annulene to be between 67 and $79 \mathrm{~kJ} \mathrm{~mol}^{-1}$ because they added an amount of up to 12 $\mathrm{kJ} \mathrm{mol}^{-1}$ for release of trans-annular hydrogen-hydrogen repulsion in the transition state; see ref. 25.

27. Calder, I. C.; Garratt, P. J. Unsaturated Monocyclic Compounds. Part XLVIII. A Study by Nuclear Magnetic Resonance of the Energy Barrier for Conformational Interconversion in Annulenes and Dehydro-Annulenes. J. Chem. Soc. B Phys. Org. 1967, 660-662.

28. Oth, J. F. M.; Gilles, J.-M.; Schröder, G. Configuration and Conformational Mobility of [12]Annulene from NMR Studies at Various Temperatures. Tetrahedron Lett. 1970, 11, 67-72.

29. Oth, J. F. M. Conformational Mobility and Fast Bond Shift in the Annulenes. Pure Appl. Chem. 1971, 25, 573-622.

30. Metcalf, B. W.; Sondheimer, F. Unsaturated Macrocyclic Compounds. LXXXVI. [20]Annulene. J. Am. Chem. Soc. 1971, 93 , 6675-6677.

31. McQuilkin, R. M.; Metcalf, B. W.; Sondheimer, F. [22]Annulene. J. Chem. Soc. D, Chem. Commun. 1971, 338-339.

32. Oth, J. F. M.; de Julien de Zélicourt, Y. Mobilité Conformationnelle et Migration Des Liaisons $\pi$ Dans Le [24]Annulène. Helv. Chim. Acta 1999, 82, 435-483.

33. (a) Sprafke, J. K.; Kondratuk, D. V.; Wykes, M.; Thompson, A. L.; Hoffmann, M.; Drevinskas, R.; Chen, W.-H.; Yong, C. K.; Kärnbratt, J.; Bullock, J. E.; Malfois, M.; Wasielewski, M. R.; Albinsson,
B.; Herz, L. M.; Zigmantas, D.; Beljonne, D.; Anderson, H. L., BeltShaped $\pi$-Systems: Relating Geometry to Electronic Structure in a Six-Porphyrin Nanoring. J. Am. Chem. Soc. 2011, 133, 17262-17273. (b) Haver, R.; Tejerina, L.; Jiang, H.-W.; Rickhaus, M.; Jirasek, M.; Grübner, I.; Eggimann, H. J.; Herz, L. M.; Anderson, H. L. Tuning the circumference of six-porphyrin nanorings. J. Am. Chem. Soc. 2019, 141, 7965-7971. (c) Liu, P.; Neuhaus, P.; Kondratuk, D. V.; Balaban, T. S.; Anderson, H. L. Cyclodextrin-Templated Porphyrin Nanorings. Angew. Chem. Int. Ed. 2014, 53, 7770-7773. (d) Liu, S.; Kondratuk, D. V.; Rousseaux, S. A. L.; Gil-Ramírez, G.; O’Sullivan, M. C.; Cremers, J.; Claridge, T. D. W.; Anderson, H. L. Caterpillar Track Complexes in Template-Directed Synthesis and Correlated Molecular Motion. Angew. Chem. Int. Ed. 2015, 54, 5355-5359.

34. Becke, A. D. Density-functional thermochemistry. III. The role of exact exchange $J$. Chem. Phys. 1993, 98, 5648-5652.

35. (a) Vydrov, O. A.; Heyd, J.; Krukau, A. V.; Scuseria, G. E. Importance of short-range versus long-range Hartree-Fock exchange for the performance of hybrid density functionals. J. Chem. Phys. 2006 , 125, 074106. (b) Vydrov, O. A.; Scuseria, G. E. Assessment of a long range corrected hybrid functional. J. Chem. Phys. 2006, 125, 234109.

36. Cohen, A. J.; Mori-Sánchez, P.; Yang, W. Insights into Current Limitations of Density Functional Theory. Science 2008, 321, 792-794.

37. Henderson, T. M.; Izmaylov, A. F.; Scalmani, G.; Scuseria, G. E. Can short-range hybrids describe long-range-dependent properties? J. Chem. Phys. 2009, 131, 044108.

38. Peeks, M. D.; Tait, C. E.; Neuhaus, P.; Fischer, G. M.; Hoffmann, M.; Haver, R.; Cnossen, A.; Harmer, J. R.; Timmel, C. R.; Anderson, H. L. Electronic Delocalization in the Radical Cations of Porphyrin Oligomer Molecular Wires. J. Am. Chem. Soc. 2017, 139, 10461-10471.

39. Peeks, M. D.; Gong, J. Q.; McLoughlin, K.; Kobatake, T.; Haver, R.; Herz, L. M.; Anderson, H. L. Aromaticity and Antiaromaticity in the Excited States of Porphyrin Nanorings. J. Phys. Chem. Lett. 2019, 10, 2017-2022.

40. Liu, P.; Hisamune, Y.; Peeks, M. D.; Odell, B.; Gong, J. Q.; Herz, L. M.; Anderson, H. L. Synthesis of five-porphyrin nanorings by using ferrocene and corannulene templates. Angew. Chem. Int. Ed. 2016, 55, 8358-8362.

41. Peeks, M. D.; Neuhaus, P.; Anderson, H. L. Experimental and computational evaluation of the barrier to torsional rotation in a butadiyne-linked porphyrin dimer. Phys. Chem. Chem. Phys. 2016, 18, $5264-5274$.

42. (a) Green, M. L. H.; Wong, L. L.; Sella, A. Relationship between Intramolecular Chemical Exchange and NMR-Observed Rate Constants. Organometallics 1992, 11, 2660-2668. (b) Jeener, J.; Meier, B. H.; Bachmann, P.; Ernst, R. R. Investigation of Exchange Processes by Two-dimensional NMR Spectroscopy. J. Chem. Phys. 1979, 71, 4546-4553. (c) Perrin, C. L.; Dwyer, T. J. Application of TwoDimensional NMR to Kinetics of Chemical Exchange. Chem. Rev. 1990, 90, 935-967.

43. Banerjee, M.; Shukla, R.; Rathore. R. Synthesis, Optical, and Electronic Properties of Soluble Poly-p-phenylene Oligomers as Models for Molecular Wires. J. Am. Chem. Soc. 2009, 131, 17801786 .

44. Lin, X.; Li, J.; Smela, E.; Yip, S. Polaron-Induced Conformation Change in Single Polypyrrole Chain: An Intrinsic Actuation Mechanism. Int. J. Quantum Chem. 2005, 102, 980-985. 
TOC graphic:

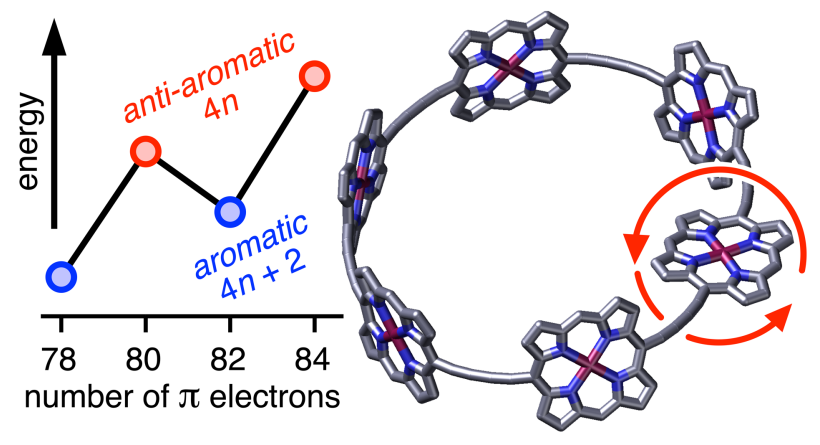

11 